Original
Article

\title{
A histological Study Comparing the Possible Protective Mechanisms of Oxytocin and Vitamin $E$ on ischemia reperfusion injury in Rat skeletal muscle
}

\author{
Samir Mahmoud Nada, Dalia Fathy El-Deeb, Alshaymaa Gamal AboulKhair and \\ Sara Adel Hosny
}

Histology Department, Faculty of Medicine, Cairo University, Cairo, Egypt

\begin{abstract}
Background: Ischemia-reperfusion (IR) injury in skeletal muscle is a pathophysiology which affect quality of life.

Aim of Work: To compare the possible protective mechanisms by which oxytocin and Vitamin E may exert on skeletal muscle IR injury in rat.

Materials and Methods: 28 male rats were divided into: Control (Group A) of 10 rats and IR group (Group B) of 18 rats. Control group underwent the same surgical steps as IR group but without clamping the femoral artery followed by the injection of one of the following [saline (AI), oxytocin (AII) or vitamin E (AIII)]. In the IR group, lower limb ischemia was induced by clamping the femoral artery. After $4 \mathrm{~h}$ of ischemia, the clamp was removed to allow reperfusion coinciding with the injection of one of the following [saline (BI), Oxytocin $(0.5 \mu \mathrm{g} / \mathrm{kg})(\mathrm{BII})$ and Vitamin E (10mg/kg) (BIII)]. After 2 hours of reperfusion, Blood samples were drawn from the femoral vein to measure glutathione (GSH) and malondialdehyde (MDA). Gastrocnemius muscles were obtained for evaluation by light and electron microscopes. Cytochrome C, Myogenin immunohistochemistry and statistical analysis were applied.

Results: A significant increase in GSH and significant decrease in MDA were reported in BII and BIII as compared to BI. Mean area \% of cytochrome C in BII and BIII showed a significant decrease compared to BI. Mean number of myogenin immunopositive cells in BII was significantly higher compared to BI. Muscular damage was proved by light and electron microscopic findings in BI. While, BII and BIII encountered evident protection from muscular damage induced by IR injury. Conclusion: Oxytocin exerts weak protective antioxidant effect against IR injury. However, it activates stem cells to regenerate the damaged muscle.

Vitamin E was better antioxidant which can react as early as 1 hour in the protection of the skeletal muscle against IR injury.
\end{abstract}

Received: 08 September 2018, Accepted: 11 September 2018

Key Words: Ischemia reperfusion, myogenin, oxytocin, skeletal muscle, vitamin E.

Corresponding Author: Sara Adel Hosny, M.D, Histology Department, Faculty of Medicine, Cairo University, Egypt, Tel.: +2 02 26126027,E-mail: dr.sara_adelh@hotmail.com

ISSN: 1110-0559, Vol. 41, No. 4

\section{INTRODUCTION:}

Ischemia-reperfusion (IR) injury occurs when blood returns to tissues following a period of deficient blood flow. Reestablishment of blood flow results in the production of free radicals and reactive oxygen species that damage the tissue $^{[1]}$.

Ischemia-reperfusion injury in skeletal muscle has complex and multifactorial mechanisms. Reestablishment of blood flow is essential to salvage ischemic tissues, but also leads to cellular damage beyond that caused by the initial ischemia ${ }^{[2]}$. Therefore, it is important for clinicians to understand IR injury in order to identify different approaches that minimize patient morbidity and mortality ${ }^{[3]}$.

Oxytocin (OXY) is a nonapeptide produced in the periventricular and supraoptical nuclei of the hypothalamus. It has been shown that OXY protects kidney, liver and rat heart against IR injuries. The anti-inflammatory and antioxidant effects of OXY on skeletal muscle tissue may cause cellular protection against oxidative stress ${ }^{[4]}$.

Vitamin E supplementation in animal studies was reported to improve antioxidant defense, suppresses oxidative stress and increases protein synthesis. Oxidative stress biomarkers such as $\mathrm{H} 2 \mathrm{O} 2$, a byproduct of lipid peroxidation and malondialdehyde (MDA) were reduced in Vitamin E treated animals, whereas antioxidants such as glutathione/glutathione disulfide (GSH/GSSG), superoxide dismutase (SOD), and catalase (CAT) were up-regulated ${ }^{[5 \& 6]}$.

The satellite cells (SCs) are defined as myogenic stem cells which are present between the basal lamina and the sarcolemma. The cross-sectional area and number of the muscle fibers are reduced following muscle damage ${ }^{[7]}$. Satellite cells of the skeletal muscles express paired-box transcription factor (Pax7) that plays an important role in regenerative myogenesis. During self-renewal and muscle 
repair, the percentage of the satellite cells expressing pax 7 increases which differentiate to more specialized myogenic precursor cells expressing myogenin. Therefore, myogenin is considered an important indicator of early differentiation of satellite cells ${ }^{[8,9}$ and 10].

Accordingly, this study was designed to compare and elicit the possible protective mechanisms by which oxytocin (OXY) and Vitamin E may exert on skeletal muscle ischemia/reperfusion [IR] injury in rat.

\section{MATERIALS AND METHODS:}

\section{Drugs:}

\section{Oxytocin (trade name Syntocinon):}

Ampule of 5 International unit $/ \mathrm{ml}[5 \mathrm{IU}$ is equivalent to $8.5 \mu \mathrm{g}$ ] (Novartis Pharma AG, Basle, Switzerland) dissolved in $47 \mathrm{ml}$ phosphate-buffered saline (PBS).

\section{Vitamin $E$ :}

Soft gelatin capsules $1000 \mathrm{mg}$ (Safe Pharma for Pharco Pharmaceuticals). The content of the capsule was drawn by a syringe and dissolved in $270 \mathrm{ml}$ of normal saline.

\section{Animals:}

This study included 28 adult male albino rats with an average body weight $170-200$ grams. They were provided by the animal house of Kasr Al-Ainy, Faculty of Medicine, Cairo University. They were housed in hygienic cages according to the guidelines for animal research issued by the National Institute of Health and approved by Animal Ethics Committee, Cairo University The rats received chow, water ad libitum.

\section{Experimental design:}

The rats were divided into the following groups:

\section{A. Control group (Group A):}

It included 10 rats that didn't undergo Ischemia/ Reperfusion [IR] injury. They were divided into 3 subgroups:

\section{- Subgroup AI (Sham Control):}

It included 4 rats that underwent the same surgical steps as mentioned in the experimental group but without clamping of the femoral artery. Two rats were injected once intraperitoneally with $0.5 \mathrm{ml}$ of normal saline and 2 rats were injected once intraperitoneally with $0.5 \mathrm{ml}$ of phosphate buffer saline.

\section{- Subgroup AII:}

It included 3 rats that underwent the same surgical steps as mentioned in the experimental group but without clamping of the femoral artery. They were injected once intraperitoneally with $0.5 \mathrm{ml}$ of Oxytocin $(0.5 \mu \mathrm{g} / \mathrm{kg})$ dissolved in phosphate buffer saline ${ }^{[11]}$.

- Subgroup AIII:
It included 3 rats that underwent the same surgical steps as mentioned in the experimental group but without clamping of the femoral artery. They were injected once intraperitoneally with $0.5 \mathrm{ml}$ of Vitamin E $(10 \mathrm{mg} / \mathrm{kg})$ dissolved in normal saline ${ }^{[12]}$.

After 2 hours from the injections, rats were sacrificed by intramuscular injection of ketamine hydrochloride $(90 \mathrm{mg} / \mathrm{kg}) /$ xylazine $(15 \mathrm{mg} / \mathrm{kg})^{[13]}$. Blood samples were drawn from the femoral vein using heparinized syringes to measure the antioxidant biomarker [glutathione (GSH)] and the oxidative stress [malondialdehyde (MDA)] biomarker. The middle parts of right and left gastrocnemius muscles were obtained.

\section{B. Ischemic/Reperfusion (IR) group (Group B):}

This group included 18 rats that were anaesthetized with an intramuscular injection of ketamine hydrochloride $(50 \mathrm{mg} / \mathrm{kg} \text {; Sigma })^{[14]}$. Following Dong et al., 2014 ${ }^{[5]}$. The lower abdomen and groin were shaved, sterilized with povidone iodine solution then the animals were placed in a supine position. A heat lamp was used to maintain the body temperature at $37.5 \mathrm{C}$ during the experiment. The right groin vessels were exposed through a transverse groin incision, and the right femoral artery was isolated by clamping with an atraumatic microvascular clamp.

After 4 hours of ischemia, the clamp was removed to allow reperfusion coinciding with injection of one of the following drugs (saline, Oxytocin, and Vitamin E).

Accordingly, this group was subdivided into:

\section{- Subgroup BI (Untreated subgroup):}

It included 6 rats, 3 rats were injected once intraperitoneally with $0.5 \mathrm{ml}$ of normal saline and 3 rats were injected once intraperitoneally with $0.5 \mathrm{ml}$ of phosphate buffer saline.

\section{- Subgroup BII (Oxytocin treated subgroup):}

It included 6 rats that were injected once intraperitoneally with $0.5 \mathrm{ml}$ of Oxytocin $(0.5 \mu \mathrm{g} / \mathrm{kg})$ dissolved in phosphate buffer saline ${ }^{[11]}$.

\section{- Subgroup BIII (Vitamin E treated subgroup):}

It included 6 rats that were injected once intraperitoneally with $0.5 \mathrm{ml}$ of Vitamin $\mathrm{E}(10 \mathrm{mg} / \mathrm{kg})$ dissolved in normal saline ${ }^{[12]}$.

At the end of 2 hours of reperfusion, sacrification, collection of blood samples as well as the middle parts of right and left gastrocnemius muscles proceeded as in group A. The muscle specimens from groups [AandB] were subjected to the following:

Part (I): Right sided specimens were fixed in $10 \%$ formol saline solution to be processed into paraffin blocks. Serial sections at 7 um thicknesses were cut using a microtome and mounted on glass slides. Other sections were mounted on positive charged slides for immunohistochemistry. 
Part (II): Left sided specimens were fixed in glutraldehyde to be prepared for electron microscopic study.

\section{- Histological study:}

(A) Light microscopic study:

Paraffin sections were subjected to the following stains:

1-Haematoxylin and Eosin ${ }^{[15]}$.

2-Immunohistochemical staining ${ }^{[16]}$.

- Anti-Cytochrome C antibody to detect apoptosis and oxidative stress.

- Anti-Myogenin antibodies to detect early differentiating myogenic precursor cells.

Muscle sections were mounted on positive charged slides, deparafinized and rehydrated. Antigen retrieval was done by boiling tissue sections in $10 \mathrm{mM}$ citrate buffer. Endogenous peroxidase activity was blocked by incubating the sections in hydrogen peroxide. Sections were incubated overnight with:

A) Rabbit polyclonal anti-Cytochrome $\mathrm{C}$ antibody (ab13575, Abcam plc, England). B) Mouse monoclonal anti-Myogenin antibody (ab212667, Abcam plc, England). The bound primary antibody was immunodetected using the labeled avidin-biotin- peroxidase complex (Histostain SP kit, Zymed Laboratories Inc, San Francisco, USA). Diaminobenzidine (DAB) was used as a chromogen and Meyer's haematoxylin as a counterstain. To establish immunohistochemical staining specificity, negative control serial sections were processed by replacing the primary antibody by phosphate buffer saline with all other steps performed in the same manner. Positive tissue control for cytochrome $\mathrm{C}$ immunostaining was human liver with a brownish cytoplasmic immunoreaction, while that of myogenin; the positive control was human rhabdomyosarcoma with a brownish nuclear reaction.

(B) Transmission electron microscope ${ }^{[16]}$ :

Small pieces of muscle specimen with average size of 1 cubic millimeter were immediately cut and rapidly fixed in $3 \%$ phosphate buffered glutraldehyde ( $\mathrm{PH} 7.2)$. Post fixed in $1 \%$ osmium tetroxide and embedded in resin. Ultrathin sections were stained by uranyl acetate followed by lead citrate. Finally examination was carried out by T.E.M. JEOL (JEM-1400 Electron Microscope) at the Electron microscope unit of Cairo University Research Park (CURP).

\section{(C) Morphometric study}

Data were obtained using "Leica Qwin 500 C" image analyzer computer system Ltd. (Cambridge, UK). The area percent of cytochrome $\mathrm{C}$ immunostained sections and the number of cells stained with myogenin antibody were measured in 10 non- overlapping fields at a magnification of $x 400$

\section{(D) Statistical Analysis}

The measurements obtained were analyzed using SPSS software version 9 (SPSS, Chicago, IL). Comparison between different groups was made using analysis of variance (ANOVA) followed by post hoc Tukey test. The results were expressed as means \pm standard deviation (SD). The differences were considered statistically significant when " $p$ value" was $<0.05$.

\section{RESULTS:}

Thebiochemical,histologicalandimmunohistochemical results of all subgroups of the control group (A) were similar. So, they were referred to by control group (subgroup AI).

\section{Biochemical results (Histogram 1):}

The mean value of serum GSH of subgroup BI (untreated subgroup; 17.87 \pm 1.01 ) and BII (Oxytocin treated subgroup; $42.98 \pm 2.07)$ were significantly lower than that of subgroup AI (control group; 59.81 \pm 1.91 ) while the mean value of serum GSH in subgroup BIII (Vitamin E treated subgroup; $58.33 \pm 1.51$ ) showed nonsignificant difference as compared with subgroup AI.

However, a statistically significant increase was reported in subgroups BII and BIII as compared to subgroup BI. Moreover, the mean value of serum GSH in subgroup BIII was significantly higher as compared to subgroups BII.

Mean serum MDA levels for subgroups BI (20.7 \pm 0.51$)$ and BII (12.8 \pm 0.22$)$ represented a significant increase when compared to control group AI $(0.98 \pm 0.1)$ while the mean serum MDA of subgroup BIII $(1.24 \pm 0.39)$ showed nonsignificant difference as compared with subgroup AI.

However, the mean values of MDA for subgroups BII and BIII were significantly decreased when compared to the subgroup BI. Moreover, a statistically significant decrease was reported in subgroup BIII as compared to subgroups BII.

\section{Histological Results: \\ Haematoxylin and Eosin Stained Sections (Plate. 1):}

Control group exhibited polyhedral muscle fibers arranged in groups; individual musclefibers were surrounded by delicate connective tissue (C.T.) endomysium. The untreated IR subgroup showed ballooned muscle fibers having pyknotic nuclei, deeply acidophilic cytoplasm with loss of myofibrils; some were fragmented and others were infiltrated by inflammatory cells separated by wide C.T. endomysium. Oxytocin treated subgroup showed few fibers with a circular outline, dark acidophilic homogenous cytoplasm and loss of myofibrils separated by wide C.T. endomysium. Vitamin E treated subgroup had apparently normal histological architecture apart of widening of C.T. endomysium.

\section{Transmission electron microscope (Plate. 2):}

Ultrathin sections of skeletal muscle in the control 
group showed alternating dark and light bands bisected by [Z] disc. Sarcoplasm contains mitochondria, glycogen granules and small cisternae of SER. Sections in the untreated IR subgroup demonstrated parts of fragmented muscle fibers; some appeared with lost cross-striational pattern and others were completely vacuolated. Enlarged mitochondria were seen with loss of some cristae. Sections in Oxytocin treated subgroup showed parallel muscle fibers with alternating dark and light bands. Disorganized myofibrils arrangement appeared at focal areas. Few mitochondria showed loss of cristae while others appeared with normal cristae. Numerous glycogen granules were clearly noted. In vitamin $\mathrm{E}$ treated subgroup, muscle fibers were regularly arranged, separated by rows of apparently normal mitochondria and numerous glycogen granules.

\section{Immunostaining with Cytochrome C (Plate. 3):}

Transverse sections of skeletal muscle in the control group demonstrated polyhedral muscle fibers with minimal cytoplasmic immunostaining by cytochrome $\mathrm{C}$ while untreated IR subgroup showed marked cytoplasmic immunostaining. Oxytocin treated subgroup revealed moderate cytoplasmic immunostaining meanwhile Vitamin E treated subgroup showed minimal cytoplasmic immunostaining.

\section{Immunostaining with myogenin (Plate. 4):}

Transverse sections of skeletal muscle in the control group showed negative nuclear immunoreactivity to myogenin while the Untreated IR subgroup exhibited a large number of positively immunostained nuclei of specialized myogenic cells in-between the polyhedral muscle fibers. Oxytocin treated subgroup as well revealed many positive immunostained nuclei. Conversely, Vitamin E treated subgroup demonstrated occasional immunostained nuclei.

Quantitative Morphometric Results (Histogram 2):

Mean Area Percentage of cytochrome $C$ immunoreactivity in the Studied Groups:

The mean area \% of cytochrome $\mathrm{C}$ in control group (subgroup AI) was $(2.06 \pm 0.56)$, subgroup BI was $(21.31 \pm 1.69)$, BII $(9.45 \pm 0.57)$ and BIII $(2.78 \pm 0.59)$. The mean area \% of cytochrome $\mathrm{C}$ immunoreactivity in muscle fibers in the experimental subgroups BI and BII was significantly increased $(P<0.05)$ when compared to the control group. Mean area $\%$ of cytochrome $\mathrm{C}$ in subgroups BII and BIII showed a significant decrease $(P<0.05)$ when compared to subgroup BI.

Mean area \% of cytochrome $\mathrm{C}$ in subgroup BIII showed a significant decrease $(P<0.05)$ when compared to subgroups BII.

\section{Mean number of myogenin immunopositive cells in the studied groups:}

Mean number of myogenin immunopositive cells in the control group AI was (1.2 \pm 0.63$)$, subgroup BI (7.2 \pm 0.79$)$, BII (10.8 \pm 0.78$)$ and BIII (2.6 \pm 0.52$)$. Number of myogenin immunopositive cells in subgroups BI, BII and BIII was significantly higher as compared to control group A.

Mean number of myogenin immunopositive cells in subgroup BII was significantly higher as compared to subgroup BI.

Mean number of myogenin immunopositive cells in subgroups BIII showed a significant decrease $(P<0.05)$ when compared to subgroups BI and BII.

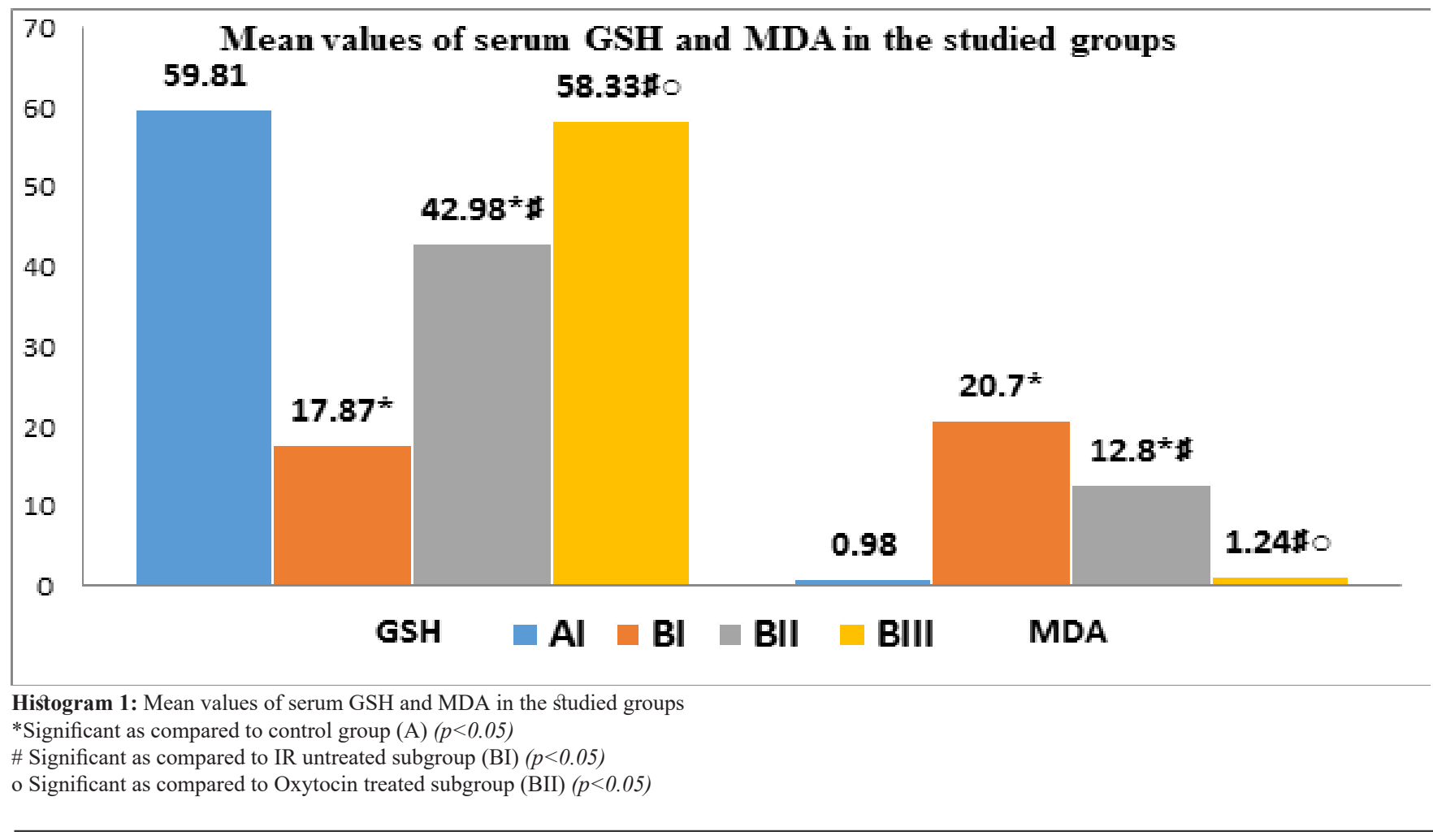




\section{Mean Area \% of cytochrome C \& mean number of myogenin imunoreactivity in the studied groups}

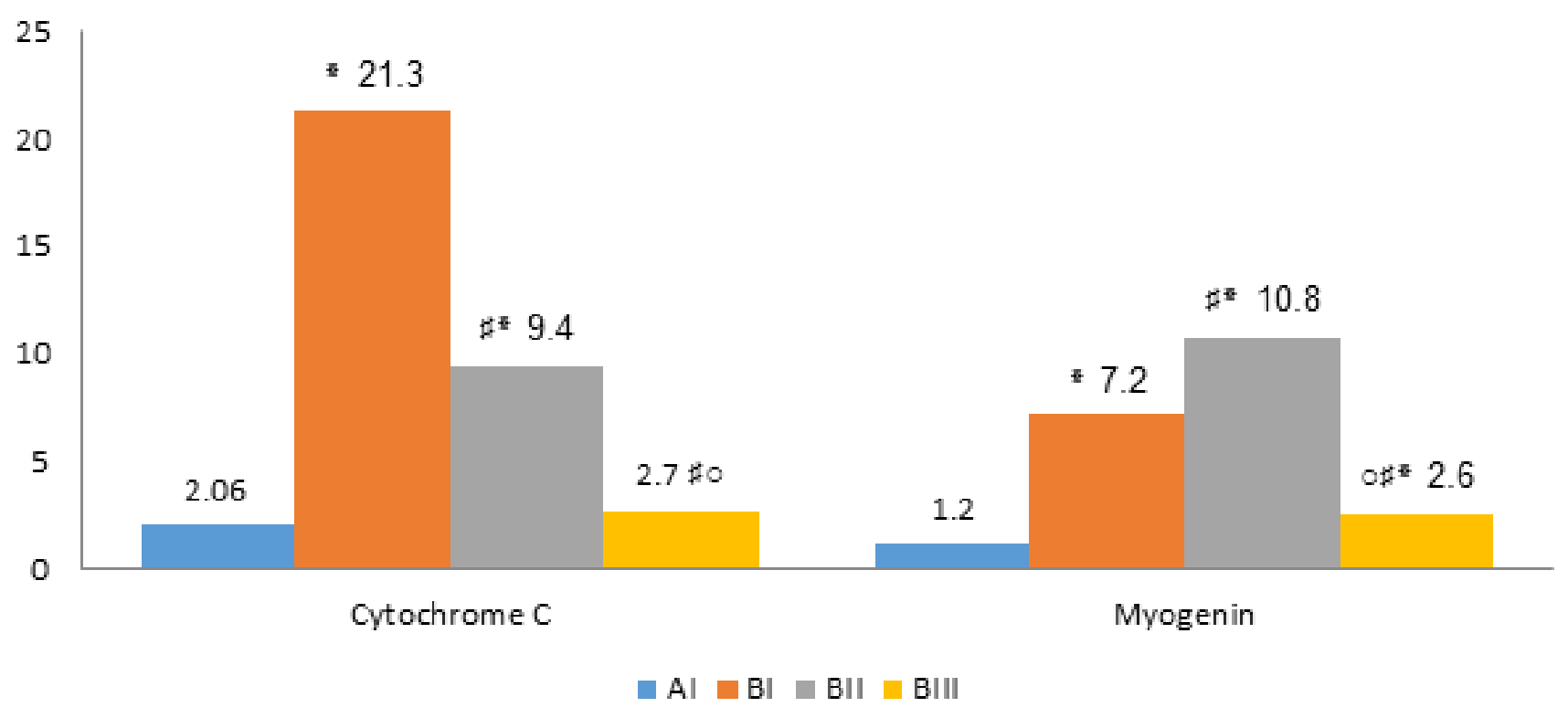

Histogram 2: Mean area \% of cytochrome $\mathrm{C}$ and mean number of myogenin immunoreactivity in the studied groups

$*$ Significant as compared to control group (A) $(p<0.05)$

\# Significant as compared to IR untreated subgroup (BI) $(p<0.05)$

o Significant as compared to Oxytocin treated subgroup (BII) $(p<0.05)$
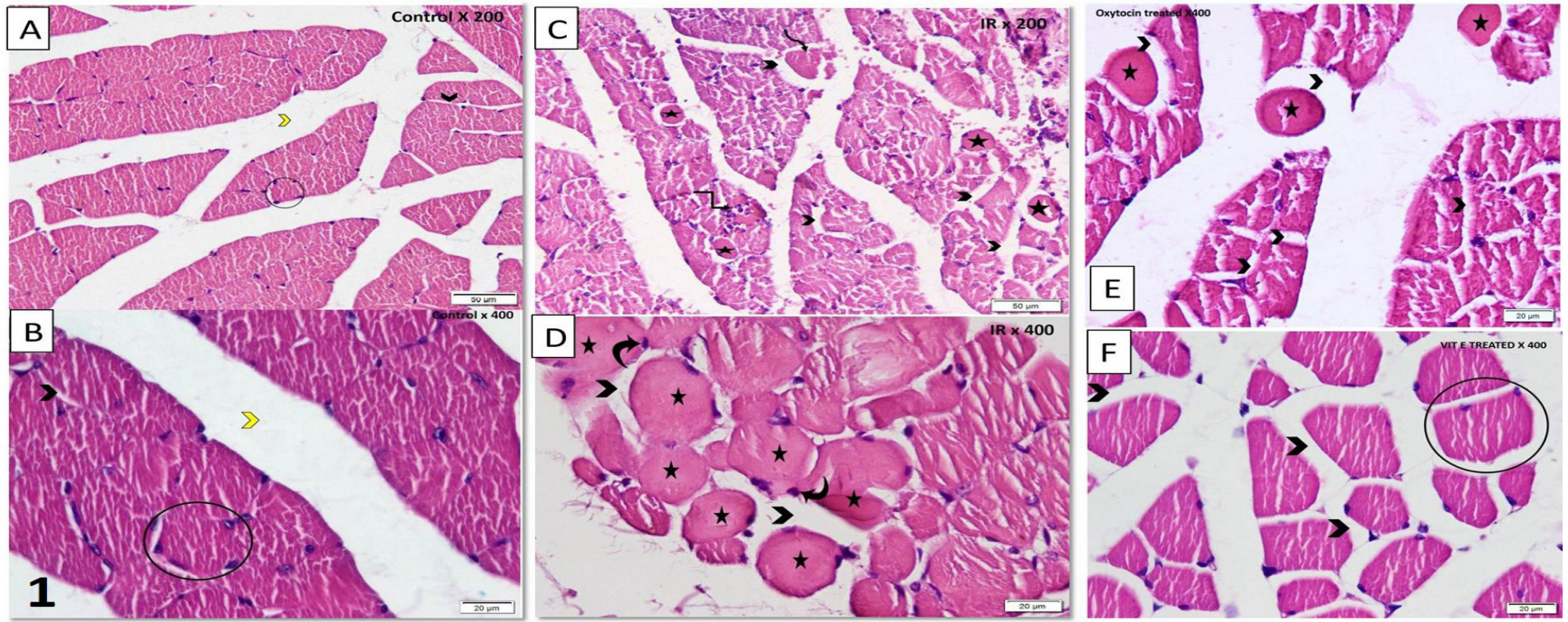

Fig. 1: Photomicrographs of T.S. section in a rat skeletal muscle of:

- AandB (control group): showing polyhedral muscle fibers with acidophilic cytoplasm and peripheral nuclei (circle). Each fiber is surrounded by C.T. endomysium (black arrowhead) while the C.T. perimysium (yellow arrowhead) wraps each fascicle.

- CandD (untreated IR subgroup): showing ballooned muscle fibers that exhibit dark acidophilic homogenous cytoplasm with loss of myofibrils (stars) and pyknotic nuclei (curved arrows). One fiber is fragmented (wavy arrow) and another one is infiltrated by inflammatory cells (kinked arrow). Note, widening of the C.T. endomysium (arrowheads).

- E (oxytocin treated subgroup): showing few fibers with a circular outline, dark acidophilic homogenous cytoplasm and loss of myofibrils (stars). Note, widening of the C.T. endomysium (arrowheads).

- F (Vitamin E treated subgroup): showing group of muscle fibers (circle) that appear almost comparable to the control apart from widening of the C.T. endomysium (arrowheads). 

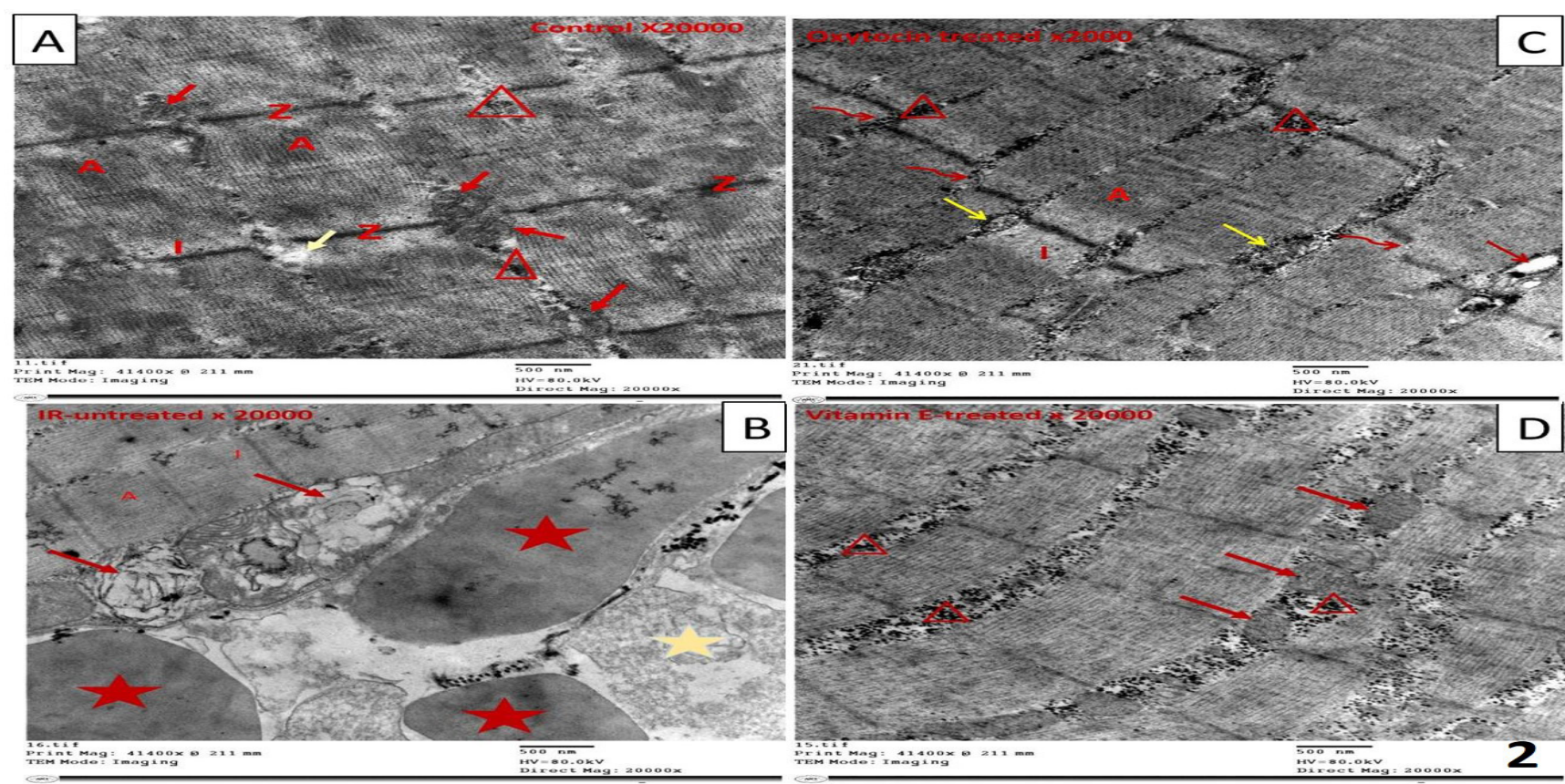

Fig. 2: Electron photomicrographs of an ultrathin section in a rat skeletal muscle of:

- A (control group): showing alternating dark (A) and light (I) bands bisected by [Z] disc. Sarcoplasm contains mitochondria (red arrows), glycogen granules (triangles) and small cisternae of SER (white arrow).

- B (untreated IR subgroup): demonstrating parts of fragmented muscle fibers; some appear with lost cross striational pattern (red stars) and others are completely vacuolated (yellow star). The upper part of the field reveals few fibers with normal alteration of light (I) and dark (A) bands. Enlarged mitochondria are seen with loss of cristae (red arrows)

- C (oxytocin treated subgroup): illustrating parallel muscle fibers with alternating dark (A) and light (I) bands. Disorganized myofibril arrangement (wavy arrows) appears at focal areas. Few mitochondria show loss of cristae (red arrows) while others appear with normal cristae (yellow arrow). Numerous glycogen granules are clearly noted (triangles).

- D (Vitamin E treated subgroup): showing parallel regularly arranged muscle fibers separated by rows of apparently normal mitochondria (red arrows) and numerous glycogen granules (triangles).
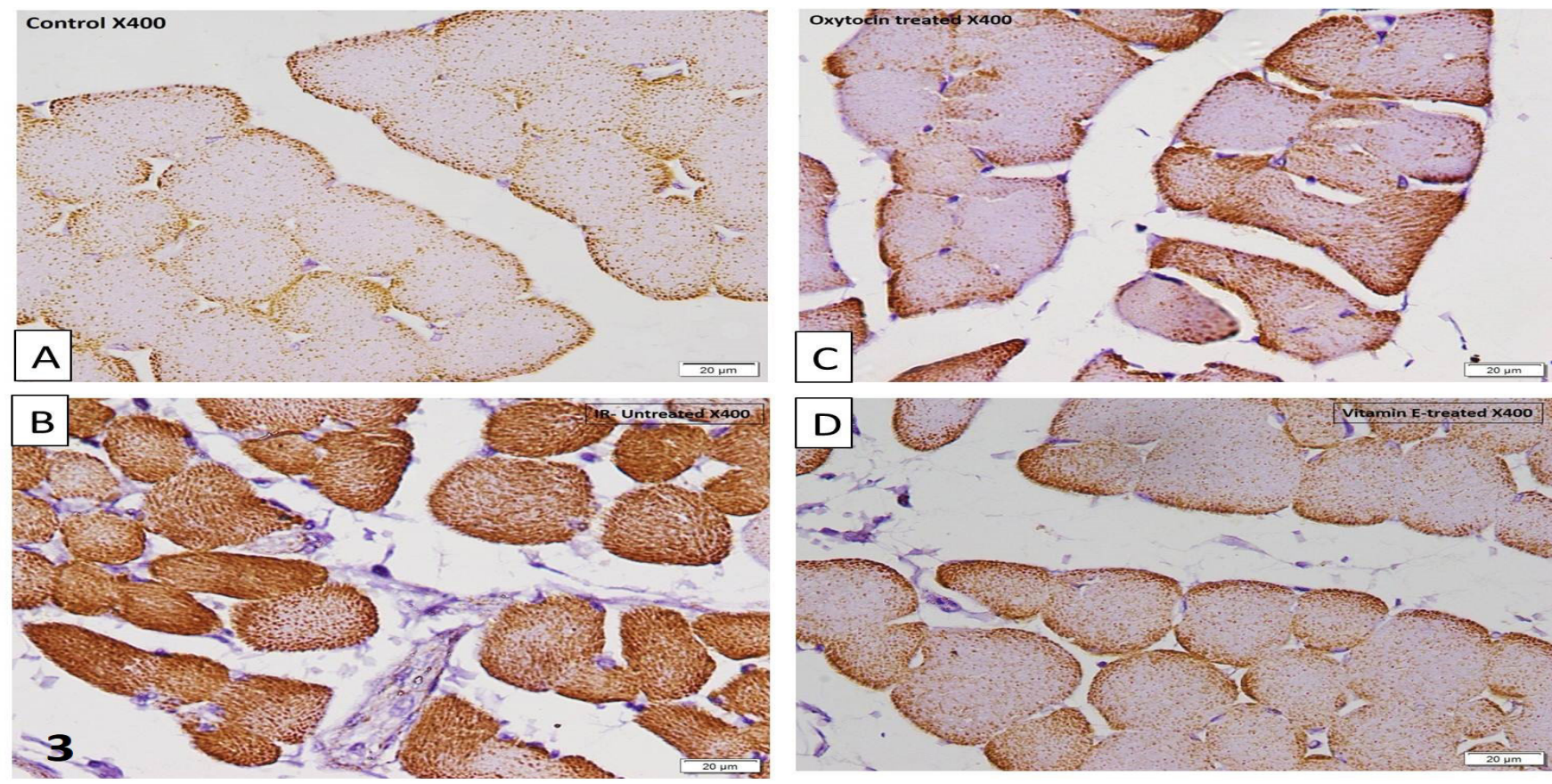

Fig. 3: Photomicrographs of TS in a rat skeletal muscle showing polyhedral muscle fibers immunostained with anti-Cytochrome C antibody:

- A (control group): minimal brownish cytoplasmic immunostaining

- B (untreated IR subgroup): marked brownish cytoplasmic immunostaining

- C (oxytocin treated subgroup): moderate cytoplasmic immunostaining

- D (Vitamin E treated subgroup): minimal cytoplasmic immunostaining 

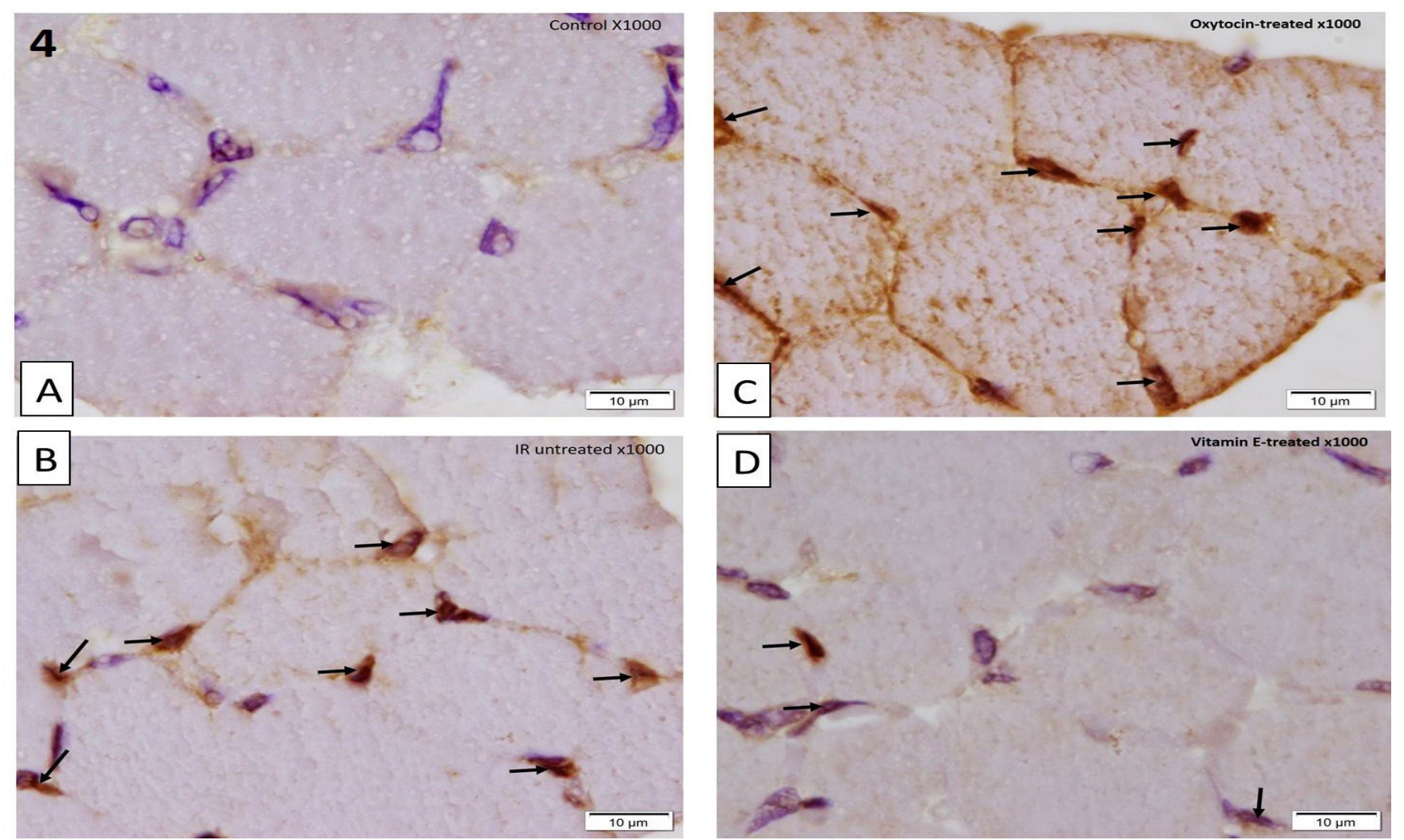

Fig. 4: Photomicrographs of TS in rat skeletal muscle immunostained with anti-myogenin antibody showing:

- A (control group): negative nuclear immunostaining

- B (untreated IR subgroup): large number of immunostained nuclei (arrows) in between the polyhedral muscle fibers.

- C (oxytocin treated subgroup): many immunostained nuclei (arrows) in between the polyhedral muscle fibers.

- D (Vitamin E treated subgroup): occasional immunostained nuclei (arrows) in between the polyhedral muscle fibers.

(Myogenin immunostaining: A, B, C and D x1000)

\section{DISCUSSION}

The skeletal muscle ischemia-reperfusion (IR) injury is a pathophysiological process due to interruption or reduction of the arterial blood supply. This condition causes a mismatch between the contributions and needs of the muscle cell that leads to local lesions. Reperfusion worsens the injury by cellular infiltration and ROS production, which leads to further tissue damage ${ }^{[1]}$.

The current study was designed to compare the possible protective mechanisms of oxytocin (OXY) versus Vitamin $E$ against skeletal muscle ischemia/reperfusion $[\mathrm{I} / \mathrm{R}]$ injury in a rat model.

In this study, the control group showed normal serological analysis and histological findings which went parallel with morphometric examination.

The untreated IR subgroup showed significant decrease of serum levels of GSH associated with significant elevation of serum level of MDA when compared with control group indicating the occurrence of oxidative stress that caused muscle damage. Malondialdehyde (MDA) is one of the most commonly used biomarkers of lipid peroxidation which reflects the extent of cellular oxidative injury, while GSH is a potent antioxidant and a major component of the antioxidant defense mechanism against oxidative stress ${ }^{[17,18]}$. These results are consistent with the findings of Erkanli et al., 2013 and Wang et al., 2015 $5^{44}$ and 19] who reported that IR injury of the skeletal muscle significantly decreased GSH activity compared with the control group while the MDA levels in IR group were significantly higher.

Light microscopic examination of skeletal muscle sections stained with HandE in untreated IR subgroup showed severe muscle fiber degeneration in the form of fragmented muscle fibers having pyknotic nuclei and deeply acidophilic cytoplasm with loss of myofibrils denoting apoptosis. Moreover, ballooning of muscle fibers, infiltration by inflammatory cells and edema were recorded in our study, these findings could be attributed to the pathological condition necrosis. These deleterious effects of IR on skeletal muscle were previously reported by Mohamed, 2015, Wang et al., 2015 and Wang et al., $2016^{[18-20]}$ who reported skeletal muscle edema, muscle fiber degeneration, pyknotic nuclei, necrosis, sarcoplasm dissolution, interstitial vessel hemorrhage and neutrophil infiltration.

The edema seen in untreated IR sections could be clarified by the endothelial damage and ROS production increasing vascular permeability to proteins and water ${ }^{[21]}$. 
Examination of the ultrathin sections of the untreated IR subgroup confirmed muscular degeneration by the presence of fragmented muscle fibers, loss of crossstriational pattern and vacuolation. Moreover, enlarged mitochondria with loss of cristae were detected. This is in accordance with Wang et al., 2015 ${ }^{[19]}$ who mentioned muscular dissolution and mitochondrial swelling in IR injury of skeletal muscles.

The mechanisms contributing to IR injury are multifactorial and complex. Calcium overload and oxidative stress play a major role. During Ischemia, muscle suffers from ATP depletion which is supplied by anaerobic glycolysis leading to production of lactate resulting in $\mathrm{H}+$ production and decrease intracellular $\mathrm{PH}$. To reestablish normal $\mathrm{PH}, \mathrm{Na}+/ \mathrm{H}+$ pump is activated to remove excess $\mathrm{H}+$ and unfortunately this leads to increased intracellular $\mathrm{Na}+$. The increased $\mathrm{Na}+$ in turn activates $\mathrm{Na}+/ \mathrm{Ca} 2+$ exchanger causing Calcium overload. This is aggravated by impairment of $\mathrm{Ca} 2+$ reuptake by sarcoplasmic reticulum which is dependent on $\mathrm{Ca} 2+\mathrm{ATPase}^{[22]}$. Increased cytosolic $\mathrm{Ca} 2+$ ions cause cell death through opening of the mitochondrial permeability transition pore (MPTP) and activation of calpain, which is cysteine proteases degrading cytoskeletal, endoplasmic reticular and mitochondrial proteins $^{[22 \& 23] .}$

Moreover, mitochondria could undergo unbalanced cycles of division (fission) and fusion in cardiac injury resulting in large fused mitochondria causing apoptotic cell death ${ }^{[24-25]}$. This could explain the presence of enlarged mitochondria with loss of cristae. In addition, calcium overload stimulates the production of cytokines and chemokines that exacerbates IR injury ${ }^{[22 \& 23]}$.

During reperfusion, oxygen levels are restored however, a surge in the generation of reactive oxygen species (ROS) occurs and neutrophils infiltrate ischemic tissues to exacerbate ischemic injury. ROS production induces expression of adhesive molecules on the microvessel endothelium and facilitates transendothelial migration of leukocytes, which in turn causes further production of ROS. The interaction between ROS and membrane lipids results in lipid peroxidation that in turn increases the membrane permeability, DNA damage and cell death ${ }^{[22}$ and 26$]$. These changes are detected in the present study as fragmented degenerated muscle fibers with pyknotic nuclei.

The previous findings were supported by examination of cytochrome C immunostained sections of untreated IR subgroup revealing marked cytoplasmic staining that was confirmed by significant increase in mean area percent of cytochrome $\mathrm{C}$ immunoreactivity versus the control group. This was clarified by Morciano et al., 2015 $5^{[27]}$ who stated that opening of mitochondrial permeability transition pore (MPTP) causes the release of various apoptogenic susbstances such as cytochrome $\mathrm{C}$ that binds to cytosolic protein forming apoptosome that activates caspase 9 , caspase 3 and caspase 7 which are responsible for destroying the cell by apoptosis.
Examination of myogenin immunostained sections of untreated IR subgroup revealed an increase in the mean number of myogenin immunostained cells compared with the control group. This was explained by Yamada et al., 2008 and Wilschut et al., 2015 ${ }^{[28 \& 10]}$ who reported that muscular injury activites satellite cells to divide and differentiate to specialized myogenic cells stained with myogenin in attempt to repair the damaged muscle.

Myogenin is a specific gene for skeletal muscle encoding a transcription factor which is detected in the primary myotome of the developing embryo and during muscle regeneration. Myogenin is expressed early in the differentiation of stem cells to specialized myogenic cells as it activates the muscle gene expression but it has no role in muscular proliferation ${ }^{[9 \& 29]}$.

In the present study, oxytocin treated subgroup showed a significant increase in serum levels of GSH and a significant decrease serum level of MDA when compared with untreated IR subgroup indicating the antioxidant effect of oxytocin. However, their levels were still significantly different from the control levels indicating mild improvement of oxidative stress.

Hand in hand with the previous findings, Erkanli et al., 2013 $3^{[1]}$ reported that the administration of oxytocin in intestinal IR injury significantly increases GSH as compared with IR group. Glutathione is an antioxidant enzyme that prevents the production of ROS and converts them into less reactive species. Moreover, oxytocin significantly decreased MDA activity as compared to IR group thus I nhibiting lipid peroxidation, which may lead to disorganization of cell structure and function.

HandE stained sections from oxytocin treated subgroup showed mild improvement indicated by clear striations of the muscle fibers. Few fibers showed areas of dark acidophilic cytoplasm and loss of myofibrils with edema.

Oxytocin has an antioxidant effect by decreasing production of ROS and damage of proteins and nucleic acid. It protects the membrane integrity against lipid peroxidation, which modifies the cell membrane permeability and fluidity to separate cells and release their organelles ${ }^{[30 \& 31]}$.

In addition, Alizadeh et al., 2012 and Chaves et al., 2013 ${ }^{[30 \& 31]}$ demonstrated that oxytocin exerts anti-inflammatory effect by decreasing infiltration of inflammatory cells and cytokines levels including vascular endothelial growth factor (VEGF), monocyte chemotactic protein-1, TNF, and IL-6.

Hand in hand with HandE, the ultrathin sections demonstrated mild improvement, showing parallel muscle fibers with alternating dark and light bands. Disorganized myofibril arrangement appeared at focal areas. Few mitochondria showed loss of cristae while others appeared with normal cristae. These results were in agreement with Erkanli et al., 2013 ${ }^{[4]}$ who demonstrated that administration of oxytocin protects the skeletal muscle tissue against 
ischemia. This was proved by moderately disorganized, degenerated muscle fibers with a minimal degree of damage in the myofibers and $\mathrm{Z}$ lines.

Moreover, numerous glycogen granules were seen in ultrathin sections that was clarified by Dianat et al., 2014 ${ }^{[32]}$ who demonstrated that IR injury causes ATP depletion that is compensated in the treated groups by increasing glycogen content of muscle for anaerobic glycolysis.

In the present study, cytochrome $\mathrm{C}$ immunostained sections of oxytocin treated subgroup revealed moderate cytoplasmic staining that were confirmed by a significant decrease in the mean area percent of cytochrome $\mathrm{C}$ immunoreactivity versus the untreated IR subgroup. This was clarified by Alizadeh et al., 2012 ${ }^{[30]}$ who stated that oxytocin inhibits mitochondrial permeability transition pore (MPTP) thus inhibiting the release of apoptogenic substances as cytochrome $\mathrm{C}$ and inhibiting apoptosis.

Examination of Myogenin immunostained sections in oxytocin treated subgroup revealed a significant increase in the mean number of myogenin immunostained cells when compared with the control and untreated IR subgroup demonstrating profound stimulatory effect of oxytocin on differentiation of stem cells. This was explained by Elabd et al., 2015 ${ }^{[33]}$ who stated that myogenic satellite cells express oxytocin receptors which are activated by oxytocin. Induction of MAPK (mitogen-activated protein kinases) by oxytocin phosphorylates extracellular signalregulated kinases (ERK-1/2). The phosphorylation of ERK promotes its kinase activity that is involved in activation and proliferation of myogenic stem cells

From the previous findings, it could be suggested that oxytocin could minimize manifestations of IR injury by its potent stimulatory effect on stem cell differentiation beside its mild anti-inflammatory and antioxidant effects as proved by light and electron microscopic studies.

A significant increase in serum levels of GSH and a significant decrease in serum level of MDA were recorded in vitamin E treated subgroup when compared with the IR untreated subgroup, Oxytocin treated subgroups. These findings reflect the antioxidant effect of vitamin E. The non-significant difference in Vitamin E treated subgroup versus the control denotes its superior antioxidant effect over oxytocin. These results were supported by the work of Dong et al., 2014 ${ }^{[5]}$ who mentioned that GSH level was increased by vitamin $\mathrm{E}$ to catalyze the conversion of ROS into less reactive species. In association, a decrease in MDA level revealed less destruction of unsaturated fatty acids in cell membranes by ROS.

Both light and electron microscopic examination of vitamin $\mathrm{E}$ treated subgroup sections showed almost normal histological muscular structure. Parallel regularly arranged muscle fibers, pale vesicular nuclei and rows of apparently normal mitochondria apart of some interstitial edema were recorded. These results were consistent with the findings of Mohamed, 2015 ${ }^{[20]}$ who stated that vitamin E treated muscle sections showed relatively normal histological architecture with normal pattern, arrangement of the myofibrils and mitochondria.

Moreover, Dianat etal., 2014 and Azari et al., 2015 $5^{[32 \& 34]}$ stated that Vitamin $\mathrm{E}$ is a strong antioxidant that acts as the first line of defence even within 1 hour by decreasing MDA, thus preventing peroxidative burst which causes destruction of the unsaturated fatty acid of the cell membranes and cellular damage. Furthermore, vitamin E increases the production of antioxidant enzymes as well as decreases pro-inflammatory cytokines.

Furthermore, Labazi et al., 2015 and Azari et al., $2015^{[35 \& 34]}$ stated that vitamin E protects the mitochondrial membrane preventing the release of apoptogenic substances as cytochrome $\mathrm{C}$ which is proved statistically in our study by a significant decrease in the mean area percent of cytochrome $\mathrm{C}$ immunostaining verus the untreated IR, oxytocin treated subgroups.

Concerning myogenin, Vitamin E treated subgroup showed a significant decrease in the mean number of myogenin immunostained cells when compared with untreated IR subgroup. However, this parameter was increased when compared to the control group. This finding illustrates weak stimulatory effect of vitamin $\mathrm{E}$ on stem cells reflecting better muscular improvement by its strong antioxidant effect. This is consistant with Avci et al., 2012 and Dong et al., 2014 ${ }^{[12 \& 5]}$ who stated that vitamin E would be hypothetically beneficial in protecting skeletal muscle against IR injury.

Moreover, Khor et al., 2016 ${ }^{[36]}$ stated that vitamin E induces satellite cell proliferation and differentiation, which was detected in this study by a significant increase in the mean number of specialized myogenic cells immunostained by myogenin in comparison with the control group.

Based upon outcomes of the current study, it could be concluded that after 6 hours of ischemia reperfusion injury, vitamin $\mathrm{E}$ is superior to oxytocin in combating skeletal muscle IR injury. This was through its potent anti-inflammatory and antioxidant effects beside its mild stimulatory effect on stem cells differentiation, which was evidenced serologically, histologically and immunohistochemically. However, longer duration of oxytocin administration may be recommended to monitor its stimulatory effect on stem cell differentiation; or even combination therapy of oxytocin and vitamin E may be advisable to achieve both antioxidant and stem cell activation benefits.

\section{REFERENCES:}

1. Delay C, Paradis S, Charles AL, Thaveau F, Chenesseau B, Zoll J, Chakfe N, Geny B and Lejay A: skeletal muscle ischemia-reperfusion and ischemic conditioning Pathophysiology - clinical applications for the vascular surgeon in JMVJournal de Médecine Vasculaire. (2017)42(1): 29-38. 
2. Armstrong DM, Armstrong Ada C, Figueiredo RC, Florentino JE, Saad PF, Fox-Talbot K, Halushka MK, Berkowitz DE, Taha MO and Fagundes DJ: Sildenafil citrate protects skeletal muscle of ischemia-reperfusion injury. Immunohistochemical study in rat model in Acta Cirúrgica Brasileira. (2013)28 (4): 282-287.

3. Zarbock A, Eroglu A, Erturk E, Ince c and Westphal M: Ischemia-Reperfusion Injury and Anesthesia in BioMed Research International. (2014) 2014: 980318.

4. Erkanli K, Erkanli Senturk G, Aydin U, Arbak S, Ercan F, Tuncdemir M, Isiksacan N and Bakir I: Oxytocin Protects Rat Skeletal Muscle against Ischemia/Reperfusion Injury in Ann Vasc Surg. (2013)27(5): 662-670.

5. Dong $X$, Xing Q, Li Y, Han X and Sun L: Dexmedetomidine protects against ischemia/ reperfusion injury in rat skeletal muscle in J Surg Res. (2014)186(1): 240-245.

6. Chung E, Mo H, Wang S, Zu Y, Elfakhani M, Rios SR, Chyu MC, Yang RS and Shen CL: Potential roles of vitamin $\mathrm{E}$ in age-related changes in skeletal muscle health in Nutrition Research. (2018) 49: 23-36

7. Le Grand F and Rudnicki MA: Skeletal muscle satellite cells and adult myogenesis in Curr Opin Cell Biol. (2007)19(6):628-633

8. Collins CA, Gnocchi VF, White RB, Boldrin L, Perez-Ruiz A, Relaix F, Morgan JE and Zammit PS: Integrated functions of Pax 3 and Pax 7 in the regulation of proliferation, cell size and myogenic differentiation in PLoS One. (2009)4(2): e4475.

9. Faralli $\mathrm{H}$ and Dilworth FJ: Turning on Myogenin in Muscle: A Paradigm for Understanding Mechanisms of Tissue-Specific Gene Expression, in Comparative and Functional Genomics. (2012)2012: 836374.

10. Wilschut KJ, Gong W, Oishi PE and Bernstein HS: Derivation of Engrafting Skeletal Muscle Precursors from Human Embryonic Stem Cells Using Serum-Free Methods in J Stem Trans Bio. (2015)1(1): 106.

11. Erkanli Senturk G, Erkanli K, Aydin U, Yucel D, Isiksacan N, Ercan F and Arbak S: The protective effect of oxytocin on ischemia/reperfusion injury in rat urinary bladder in Peptides. (2013)40: 82-88.

12. Avci G, Kadioglu H, Sehirli A, Bozkurt S, Guclu O, Arslan E and Muratli SK: Curcumin Protects Against Ischemia/Reperfusion Injury in Rat Skeletal Muscle in J Surg Res. (2012)172(1): e39-46.
13. El-Akabawy G and El-Kholy W: Neuroprotective effect of ginger in the brain of streprozotocininduced diabetic rats in Ann Anat. (2014)196(23):119-128.

14. Struck MB, Andrutis KA, Ramirez HE and Battles AH.: Effect of a short-term fast on ketaminexylazine anesthesia in rat in J Am Assoc Lab Anim Sci. (2011)50(3):344-8.

15. Kiernan J: Histological and Histochemical Methods: Theory and Practice.5th ed., Scoin publisher, United Kingdom. (2015) pp: 111-162.

16. Suvarna SK, Layton C and Bancroft JD: Bancroft's theory and practice of histological techniques, 7th edition .Elsevier Health sciences, Churchill Livingstone. (2012) pp.381-426 and 493-538.

17. Nyberg M, Mortensen SP, Cabo H, Gomez-Cabrera MC, Viña J and Hellsten Y: Roles of sedentary aging and lifelong physical activity in exchange of glutathione across exercising human skeletal muscle in Free Radic Biol Med. (2014)73:166-73.

18. Wang L, Shan Y, Chen L, Lin B, Xiong X, Lin L and Jin L: Colchicine protects rat skeletal muscle from ischemia/reperfusion injury by suppressing oxidative stress and inflammation in Iran J Basic Med Sci. (2016)19(6): 670-675.

19. Wang XT, Tian Y, Xu WX, Cui LH, Xiang SY and Lü SC: Protective Effects of Modeled Superoxide Dismutase Coordination Compound (MSODa) Against Ischemia/Reperfusion Injury in Rat Skeletal Muscle in Cell Physiol Biochem. (2015)37(2): 465-476.

20. Mohamed EA: The Protective Effect of Melatonin vs. Vitamin E in the Ischemic/ Reperfused Skeletal Muscle in the Adult Male Rat Model in J Cytol Histol. (2015)s3:005.

21. Aghajanian A, Wittchen ES, Allingham MJ, Garrett TA and Burridge K:Endothelial cell junctions and the regulation of vascular permeability and leukocyte transmigration. in J Thromb Haemost. (2008)6(9):1453-1460.

22. Kalogeris T, Baines C, Krenz M and Korthuis RJ: Cell Biology of Ischemia/Reperfusion Injury in Int Rev Cell Mol Biol. (2012)298: 229-317.

23. Halestrap AP: Calcium, mitochondria and reperfusion injury: a pore way to die in Biochem. Soc. Trans. (2006)34(Pt2): 232-237.

24. Chen L and Knowlton AA: Mitochondria and heart failure: new insights into an energetic problem in Minerva Cardioangiol. (2010)58: 213-229.

25. Ong SB, Subrayan S, Lim SY, Yellon DM, Davidson SM and Hausenloy DJ: Inhibiting 
mitochondrial fission protects the heart against ischemia/reperfusion injury in Circulation. (2010)121(18): 2012-2022.

26. Kirisci M, Oktar GL, Ozogul C, Oyar EO, Akyol SN, Demirtas CY and Arslan M.: Effects of adrenomedullin and vascular endothelial growth factor on ischemia/reperfusion injury in skeletal muscle in rats in J Surg Res. (2013)185(1): 56-63.

27. Morciano G, Giorgi C, Bonora M, Punzetti S, Pavasini R, Wieckowski MR, Campo $G$ and Pinton P: Molecular identity of the mitochondrial permeability transition pore and its role in ischemia-reperfusion injury in J Mol Cell Cardiol. (2015)78: 142-153.

28. Yamada M, Sankoda Y, Tatsumi R, Mizunoya W, Ikeuchi Y, Sunagawa K and Allen RE: Matrix metalloproteinase-2 mediates stretch-induced activation of skeletal muscle satellite cells in a nitric oxide-dependent manner in Int. J. Biochem. Cell Biol. (2008)40(10): 2183-2191.

29. Yin H, Price F and Rudnicki MA: Satellite cells and the muscle stem cell niche in Physiol Rev. (2013)93(1): 23-67.

30. Alizadeh AM, Faghihi M, Khori V, Sohanaki $\mathrm{H}$, Pourkhalili K, Mohammadghasemi $\mathrm{F}$ and Mohsenikia M: Oxytocin protects cardiomyocytes from apoptosis induced by ischemia-reperfusion in rat heart: role of mitochondrial ATP-dependent potassium channel and permeability transition pore in Peptides. (2012)36(1): 71-77.

31. Chaves VE, Tilelli CQ, Brito NA and Brito MN:
Role of oxytocin in energy metabolism in Peptides. (2013)45: 9-14.

32. Dianat M, Esmaeilizadeh M, Badavi M, SamarbafZadeh AR and Naghizadeh B: Protective effect of Crocin on Ischemia-reperfusion induced Oxidative Stress in Comparison With Vitamin E in Isolated Rat Hearts in Jundishapur J Nat Pharm Prod. (2014)9(2): e17187.

33. Elabd C, Cousin W, Upadhyayula P, Chen RY, Chooljian MS, Li J, Kung S, Jiang KP and Conboy IM: Oxytocin is an age-specific circulating hormone that is necessary for muscle maintenance and regeneration in Nat Commun. (2014)5: 4082.

34. Azari O, Kheirandish R, Azizi S, Farajli Abbasi M, Ghahramani Gareh Chaman S and Bidi M: Protective Effects of Hydrocortisone, Vitamin $\mathrm{C}$ and $\mathrm{E}$ Alone or in Combination against Renal Ischemia-Reperfusion Injury in Rat in Iran J Pathol. (2015)10(4): 272-280.

35. Labazi M, McNeil AK, Kurtz T, Lee TC, Pegg RB, Angeli JPF, Conrad M and McNeil PL: The antioxidant requirement for plasma membrane repair in skeletal muscle in Free Radic Biol Med. (2015)84: 246-253.

36. Khor SC, Razak AM, Wan Ngah WZ, Mohd Yusof YA, Abdul Karim N and Makpol S: The Tocotrienol-Rich Fraction Is Superior to Tocopherol in Promoting Myogenic Differentiation in the Prevention of Replicative Senescence of Myoblasts in PLoS One. (2016)11(2): e0149265. 


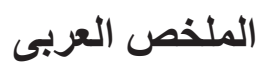

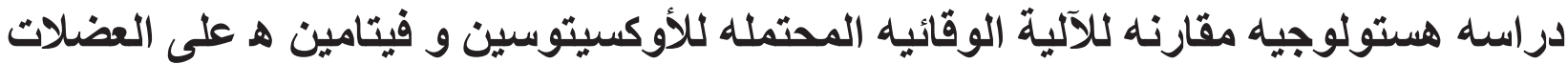

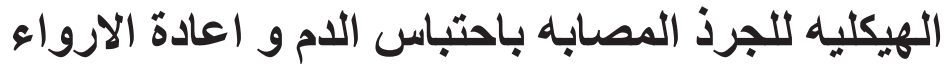

سمير محمود ندا، داليا فتحي الديب، الشيماء جمال أبو الخير، سارة عادل حسني

\section{قسم الههتولوجيا ـ كلية الطب - جامعة القاهرة}

الخلفيه: يعتبر إحتباس الدم و إعادة الإرواء للعضلات الهيكليه حاله باثوفسيولوجيه مما يؤثر على جودة الحياة بطريقه مباشره.

الهـف من العمل: لمقارنة وتوضيح الطرق الوقائيه المحتمله التي قد يحدثها الأوكسيتوسين وفيتامين هـ على العضلات الهيكليه

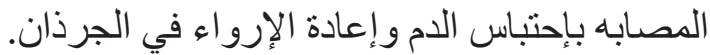

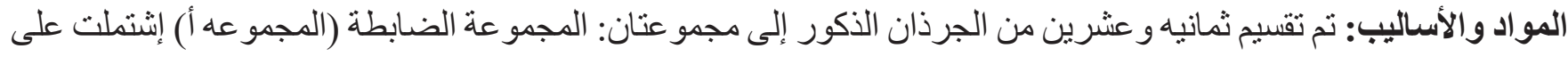

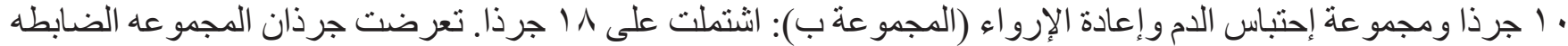

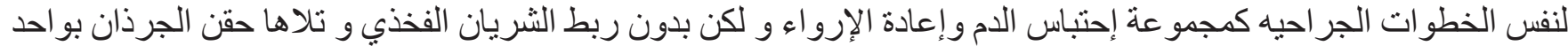

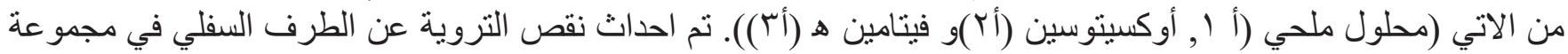

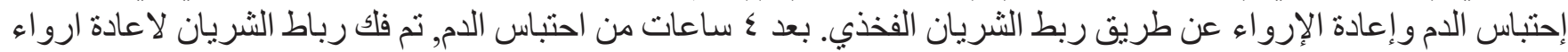

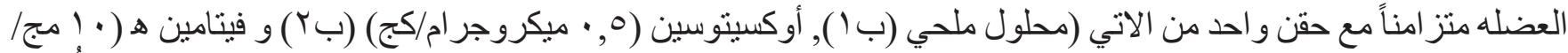

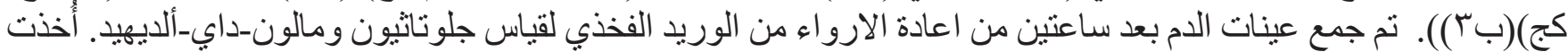

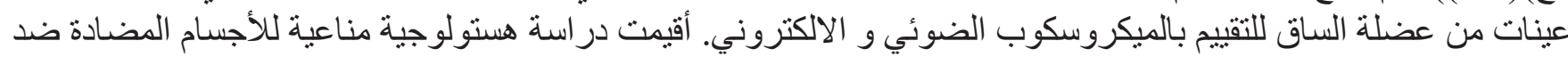
سيتوكروم سي و ضد الميوجينين و أقيمت در اسات كميه قياسياه.

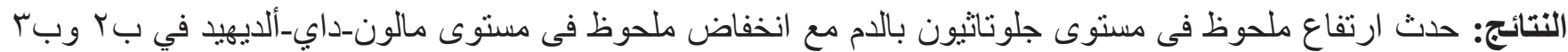

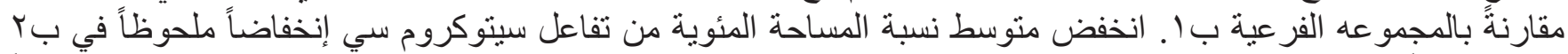

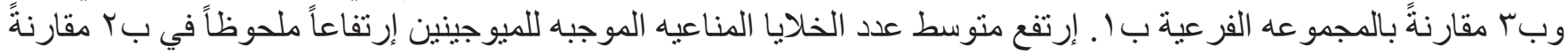

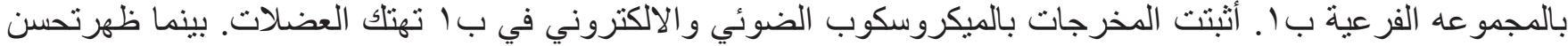

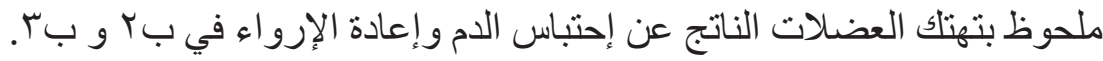

الاستنتاج: يقوم الأوكسيتوسين بتأثثر وقائي مضاد للاكسده ضعيف ضد إحتباس الدم و إعادة الإرواء. ولكنه مع ذلك ينشط الخلايا

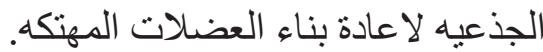
وكان فيتامين هـ مضاد للاكسده أفضل حيث انه يتفاعل مبكر ا في خلال ساعه لحماية العضلات الهيكليه ضد إحتباس الدم و إعادة الإرو اء. 